\title{
The Persistence of the Leveling Down Objection
}

\author{
MICHAEL WEBER \\ Bowling Green State University
}

\begin{abstract}
According to the Leveling Down Objection, some, if not all, egalitarians must concede that leveling down can make things better in a respect-in terms of equality. I argue, first, that if this is true, then it is hard for such egalitarians to avoid the even more disturbing result that leveling down can be better all-things-considered. I then consider and reject two attempts to take this particular sting out of being an egalitarian. The first is Tom Christiano's argument that the egalitarian is not forced to concede that the leveled down state is better with respect to equality, on the grounds that if equality with respect to any $\mathrm{X}$ matters, e.g. welfare, then value must be assigned to $X$, rendering the leveled down state inferior even with respect to equality. This is insufficient, I argue, to justify his requirement that Pareto-inferior states cannot be better with respect to equality. The second, offered by both Ingmar Persson and Campbell Brown, is to argue that prioritarianism-a central rival to egalitarianism-is also subject to the Leveling Down Objection. Persson and Campbell fail, I claim, because their arguments turn on increases in measures in leveled down states that have no value on the prioritarian view.
\end{abstract}

Keywords: Leveling Down Objection, egalitarianism, prioritarianism, Tom Christiano, Pareto-efficiency, conditional egalitarianism

JEL Classification: D630

\section{INTRODUCTION}

The Leveling Down Objection has convinced many to reject egalitarianism. The objection, put simply, is that egalitarians must accept, implausibly, that it is an improvement, at least in some respect, if the better-off are reduced to the level of the worse-off without the worse-off becoming any better off. Egalitarians have responded to the

AUTHOR's NoTE: For valuable feedback on earlier versions of this paper, I thank David Dick and audiences at the 2016 Pacific Division meeting of the American Philosophical Association, Wayne State University, and the 2016 meeting of the Philosophy, Politics, and Economics Society. I also received helpful feedback from anonymous referees for this journal. 
Leveling Down Objection in a number of ways. One of the most interesting is Tom Christiano's (2008) argument that the value of equality and the value of what is to be equalized, e.g. welfare, are deeply intertwined, such that it is not in any respect better if the better-off are reduced to the level of the worse-off without the worse-off becoming any better off. The resulting view appears to be a brand of what Andrew Mason (2001) calls Conditional Egalitarianism, according to which (greater) equality has final (or non-instrumental) value if and only if some are better off. Another interesting response, suggested independently by Ingmar Persson (2013) and Campbell Brown (2003), suggests that being subject to the Leveling Down Objection is not so bad because attractive alternative views such as prioritarianism are similarly subject to the Leveling Down Objection. Though both of these responses are interesting, neither is ultimately successful, or so I shall argue. A bit of background is required first, and is provided below.

It should be said, even before that, that if the egalitarian responses to the Leveling Down Objection that I discuss do indeed fail, it does not mean that egalitarianism must be rejected. First, as I will explain below, some egalitarian views-namely, those that are deontic-may be able to dismiss the Leveling Down Objection as simply inapplicable, though I cast a bit of doubt on this. Second, other egalitarians-so-called telic egalitarians-can simply bite the bullet and accept the consequence that a leveled-down state is better in a certain respect. This may be a hard bullet to bite, especially if, as I will argue, it is difficult to allow that a leveled down state is better in a respect without exposing oneself to the possibility that it is better all-things-considered. But the thrust of my argument is that recent attempts to avoid the Leveling Down Objection are inadequate, and thus biting this particular bullet may be unavoidable.

\section{The LeVEling Down OBJeCtion}

As just suggested, there are many different egalitarian views. It is common, following Derek Parfit (1997), to divide them into the two broad categories I identified above: telic (short for teleological) egalitarianism and deontic (short for deontological) egalitarianism. Parfit says that telic versions of egalitarianism are those that accept that it is 
bad in itself if some people are worse off than others. ${ }^{1}$ Deontic versions of egalitarianism, in contrast, deny that it is bad in itself if some people are worse off than others. Rather, according to deontic versions of egalitarianism, inequality is unjust when it is the result of wrong-doing by some person, persons, or human institution. In such a case, as Parfit emphasizes $(1997,208)$, it is not the inequality itself-the state of affairs in which some are worse off than others-that it unjust; rather, it is the way in which it was produced, or came about.

Some have complained that there are egalitarian views that do not fit into either of Parfit's categories-that Parfit's categories are inadequate to capture the full range of egalitarian views. Mason (2001), for instance, argues that his Conditional Egalitarianism does not fit into either category. It doesn't fit into the teleological category because it denies that it is always bad in itself if some people are worse off than others. However, definitions of telic egalitarianism broader than Parfit's could encompass Mason's Conditional Egalitarianism while maintaining the key teleological focus on the value of states of affairs. Martin O'Neill (2008) complains that instrumental versions of egalitarianism are excluded. O'Neill is right, though Parfit's categories were proposed only to categorize different non-instrumental versions of egalitarianism. ${ }^{2}$

Be that as it may, Parfit (2007) argues-and many have followed him in arguing-that at least telic egalitarianism has a troubling consequence: in at least one respect, namely, with respect to equality, an initially unequal situation can be improved by simply reducing the better-off to the level of the worse-off, as in Figure 1, in which (following a well-established convention) the width of each column represents the size of a given population or sub-population and the height represents that population's level of welfare (or whatever one takes to be the appropriate object of equalization, e.g., resources, opportunity for welfare, or capabilities). ${ }^{3}$

\footnotetext{
${ }^{1}$ Frequently it is added that inequality is bad in itself only if it is not the product of choices people make, or is otherwise their fault. This does not bear on present concerns.

${ }^{2}$ My interest here is limited to non-instrumental versions of egalitarianism, which have received the most philosophical attention in recent years. Instrumental egalitarianism is clearly not subject to the Leveling Down Objection, and may be the preferred egalitarian view for that reason, as O'Neill has argued.

${ }^{3}$ The objection need not be stated in terms of one state being transformed into another. It can be made simply by suggesting that at least telic egalitarianism has the consequence that state of affairs B in Figure 1 is better than state A with respect to equality. So too with the examples to follow.
} 


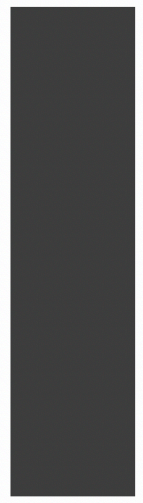

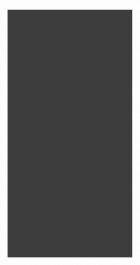

A
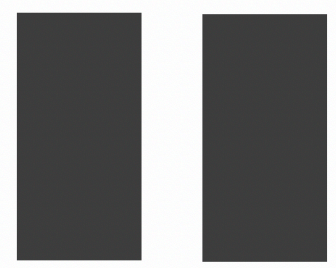

B

Figure 1. Leveling down ${ }^{4}$

The Leveling Down Objection is the suggestion that this is an unacceptable consequence. A common way to support the Leveling Down Objection is to appeal to a principle according to which one situation or state of affairs cannot be better than another in any respect if no one is better off (and similarly cannot be worse in any respect if no one is worse off), though some think that a weaker principle is sufficient. $^{5}$

There are less extreme cases of leveling down that seem no less troubling. For instance, inequality can be reduced by lowering the level of the better-off some, but not enough to lower them to the level of the worse-off, as in Figure 2.

\footnotetext{
${ }^{4}$ To avoid complications associated with Parfit's Non-Identity Problem, it is to be assumed that it is the same set of people in states A and B.

${ }^{5}$ Parfit (1997) calls the wider principle the person-affecting principle; Larry Temkin (2002) calls it The Slogan. Temkin (1987, 1993a, 2002, 2003a, 2003b) has argued that we should reject The Slogan. However, this is controversial, and engaging in the controversy is beyond the scope of this paper. Nils Holtug (2007b), among others, argues that the Leveling Down Objection does not rest on The Slogan, but rather on a narrower and more defensible relative of it. Roger Crisp (2003a, 2003b) argues similarly. As such, the Leveling Down Objection cannot be simply dismissed by casting doubt on The Slogan.
} 


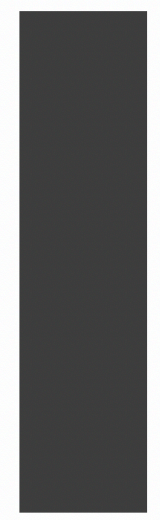

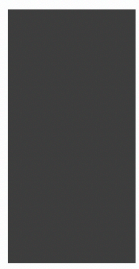

A

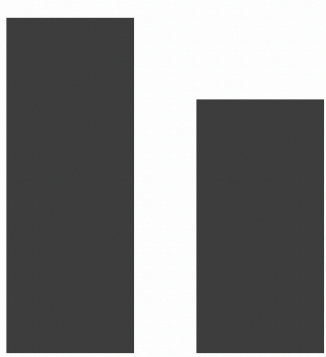

B

Figure 2. Partially levelling down

It is also leveling down if the levels of both the better-off and the worse-off are reduced, but the level of the better-off is reduced more. To be an instance of leveling down, all that is required is that inequality is reduced in virtue of some being made worse off without any others being made better off. ${ }^{6}$

Some, including Parfit (1997), think that deontic egalitarianism is immune to the Leveling Down Objection because it denies that inequality is bad in itself, and thus is not committed to saying that less unequal states are at least in one way better than more unequal states. Though I will not go into the matter in much detail here, it seems that nonetheless deontic egalitarianism is subject to an analogous objection. For if there is an unjust inequality, then the deontic egalitarian seems committed to the claim that rectifying the injustice is a moral improvement, even though no one is made better off. Some do not find this as paradoxical as the claim that one state of affairs can be better than another even if no one is better off. There is considerable controversy about this matter, and I do not propose to settle it here. ${ }^{7}$ If deontic egalitarianism is indeed immune to the Leveling Down Objection

\footnotetext{
${ }^{6}$ Temkin (1993b) has taught us that it is often very difficult to determine when inequality has been increased or reduced, because it is a complex notion. So it may often be difficult to determine in a given instance whether it is a case of leveling down. The cases I employ, however, do not give rise to such complications.

${ }^{7}$ Kasper Lippert-Rasmussen (2007) and Martin O'Neill (2008) both argue that deontic egalitarianism is equally subject to the Leveling Down Objection (or some analogous objection). However, Michael Otsuka and Alex Voorhoeve (2009, 183-184) advance a deontic egalitarian view grounded in the contractarian idea that allocations must be justifiable to each person taken separately that they claim is immune to the Leveling Down Objection.
} 
or close analogues, then it falls outside the scope of my present concerns.

In large part because of the Leveling Down Objection, a lot of people with egalitarian (and teleological) leanings have adopted, instead, what Parfit (1997) has dubbed the Priority View, or prioritarianism. ${ }^{8}$ Prioritarianism is the view that benefitting people matters more the worse off people are in absolute terms. This is held to be a superior view because it a) tends toward equality in virtue of the priority it gives to benefiting those who are worse off (in absolute terms), and b) is immune to the Leveling Down Objection because, as with (orthodox) utilitarianism, the only way to improve a situation is to make someone better off.

Some egalitarians, however, have stood their ground. Larry Temkin (2002), for instance, argues that while the leveled down state may be better with respect to equality, it does not follow that (even telic) egalitarians are committed to the claim that the leveled down state is better all-things-considered, because egalitarians can be pluralists, assigning final (or non-instrumental) value to both equality and welfare. ${ }^{9}$ So long as the loss in terms of welfare outweighs (or otherwise defeats) the gain in terms of equality, the leveled down state will be worse allthings-considered. Therefore, egalitarians can be what Parfit calls Moderate Egalitarians, maintaining that "though it would always be in one way better if there ceased to be inequality between different people [or inequality was reduced], this outcome would be worse all-thingsconsidered if it would be worse for some people and better for no one" (Parfit 2012, 399). Moderate egalitarians, then, concede only that the leveled down state of affairs is better in a respect, and claim that this is not so bad. ${ }^{10}$

Parfit disagrees, arguing that it is more than a little troubling if egalitarianism has the result that a leveled down state is better in a respect, even if it is not better all-things-considered. It is, he says, a significant objection, even if not a decisive objection (401). His argument is that it is not enough when evaluating a moral theory to consider only what it deems better or worse, or right or wrong, all-things-considered. He insists that "we should reject moral theories which make implausible

\footnotetext{
${ }^{8}$ As Parfit notes, and others such as Andrew Williams (2012) have emphasized, deontic versions of prioritarianism are possible, though most of its well-known advocates defend teleological versions.

${ }^{9}$ Temkin $(1987,1993 a, 2002,2003 a, 2003 b)$ has offered a variety of other responses to the Leveling Down Objection, including, as noted earlier, arguing that we should reject The Slogan.

${ }^{10}$ I am grateful to David Dick for emphasizing this point to me.
} 
claims about which are the facts that can make outcomes better or worse, or can make acts right or wrong" (400). And while it is not absurd, Parfit thinks it is disturbing to accept that if everyone became equally badly off, that would make an outcome in some way better. ${ }^{11}$ As such, he concludes, the Leveling Down Objection has "considerable force" (401). Roger Crisp (2003a) and Mason (2001, 252), among others, agree.

It seems to me, however, that Parfit may underestimate the problem with Moderate Egalitarianism. According to Moderate Egalitarianism, a leveled down state can be better in some respect but it cannot be better all-things-considered. But this requires that the loss in terms of welfare is always more significant morally than whatever gains there are in terms of equality. Surely the Moderate Egalitarian must provide a justification for assigning this kind of priority to welfare over equality (and not in an ad hoc way). ${ }^{12}$ Barring that, it seems that it must be conceded that if a leveled down state can be better in a certain respect, then it is at least possible that it is better all-things-considered. As such, Moderate Egalitarianism appears to be an unstable position. ${ }^{13}$

In fact, it can be argued that things are even worse than that for Moderate Egalitarianism. Temkin (2002, 2003a, 2003b) has argued that there are a number of values that, like equality, entail that leveling down can bring about an improvement in some respect. ${ }^{14}$ Imagine, for instance, that on some relevant metric A is more deserving than B (in the extreme, A is a saint and B is a sinner), yet B is better off. Plausibly, it would be better with respect to desert if $B$ were worse off, if, for instance, he were leveled down so that he is worse off than A. If Temkin is right that there are many values other than equality that are better realized through leveling down-and I think he is-then leveling down can bring about an improvement in a variety of respects, in which case it

\footnotetext{
${ }^{11}$ Against deontic egalitarians, it could be put this way: it is disturbing, if not absurd, to think that there can be a moral improvement if everyone became equally badly off.

${ }^{12}$ Parfit (1997) suggests one reason for thinking that in leveling down cases the losses in terms of welfare will outweigh or otherwise defeat the gains in terms of equality. The idea, roughly, is that for any large increase in equality in a leveling down case there must also be a large decrease in welfare. I am not convinced by this for two reasons, however. First, as indicated previously, Temkin (1993b) has shown that equality is quite complex. As such, there is no guarantee that large increases in equality necessarily require large decreases in welfare. Second, even if it is true that large gains in equality require large losses in welfare, this does not guarantee that disvalue of the losses in terms of welfare is greater than the value of the gains in terms of equality.

${ }^{13}$ This has also been noted by Dennis McKerlie (1996) and Bertil Tungodden (2003, 10).

${ }^{14}$ Temkin refers to such values as impersonal values.
} 
seems all the more difficult to be absolutely confident that leveling down cannot be an improvement all-things-considered. Moderate Egalitarianism requires an argument that what is lost in leveling down is always morally more important than what is gained. This is a tall order..$^{15}$

\section{Christiano’s DefEnSE of EgAlitARIANISM}

If what I have said about Moderate Egalitarianism is true, then (telic) egalitarians cannot happily allow that the leveled down state can be better in a certain respect, as this exposes them to the possibility that the state is better all-things-considered. This is what makes Tom Christiano's response to the Leveling Down Objection in The Constitution of Equality: Democratic Authority and its Limits so interesting, as he argues that leveling down does not even make things better in some respect-not even with respect to equality.

Christiano's case for his view that leveling down is not an improvement from an egalitarian point of view has two major components. First, he argues that the value of welfare (or whatever else one takes to be the proper object of equalization) is "built into" the principle of equality (Christiano 2008, 33). There is, he says, "an internal connection between the rationale for equality and the value of the relevant fundamental good that is equalized" (33). He argues for this connection with a compelling example. Imagine that there is enough bread to give every person more bread than he or she could possibly use (in which case the bread that one did not eat or otherwise use would have no trade-value). There is, then, a surplus of bread after each person has been given as much as he or she could possibly use. Christiano claims, quite plausibly, that it simply does not matter how this surplus is distributed, in particular whether it is distributed equally or not (or not distributed at all). For the equal distribution of the bread only matters, if it matters at all, if the bread has value to the potential recipients. More generally, it is only if more $\mathrm{X}$ is better than less that equality with respect to $\mathrm{X}$ matters. ${ }^{16}$ As Christiano puts it, "a necessary condition for equality mattering is that the thing being equalized is such

\footnotetext{
${ }^{15}$ Indeed, one of the main points of this paper is to show just what a tall order it is. See sections III and IV.

${ }^{16}$ Christiano misses that with things of negative value, e.g., pain or punishment, equality can matter even though more is not better than less. He could unproblematically modify the view to be 'it is only if more $\mathrm{X}$ is better than less, or less better than more, that equality with respect to $\mathrm{X}$ matters'.
} 
that more is better than less" (34). Thus, if equality with respect to X matters, it must be that more $\mathrm{X}$ is better than less. ${ }^{17}$ Thus, Christiano claims, an egalitarian (with respect to welfare) cannot be indifferent between two perfectly equal states when one has members at a higher level of welfare, as in the Figure 3 below. ${ }^{18}$

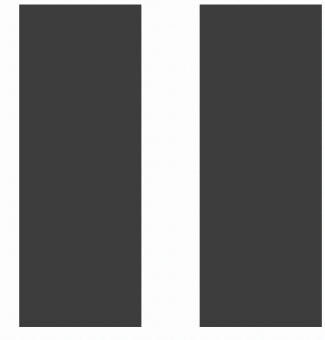

A

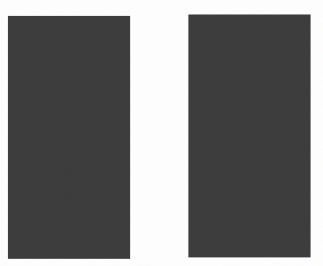

B

\section{Figure 3. Perfectly equal states with different levels of welfare}

The egalitarian must prefer state of affairs A, according to Christiano, because while there is no difference between A and B in terms of the equality of the distribution of welfare, A has greater (total and average) welfare. In a simplified two-person world, then, the egalitarian must prefer a world in which both people are at a welfare level of five $(5,5)$ to a world in which both people are at a welfare level of $3(3,3)$, as in Figure 4.

\begin{tabular}{ccc}
\hline & \multicolumn{2}{c}{ State of affairs } \\
\cline { 2 - 3 } Person & S1 & S2 \\
\hline A & 5 & 3 \\
B & 5 & 3 \\
\hline
\end{tabular}

\footnotetext{
${ }^{17}$ Some positive values are not such that more is better than less. Friendship, for example, is valuable, but it does not follow that one should try to maximize the number of friends one has (though perhaps one should maximize the quality of the friendships one does have). On Christiano's view, equality with respect to such values cannot matter (because more is not better than less). This might be thought to be a dubious consequence.

${ }^{18}$ This is significant because egalitarians tend to think that egalitarianism itself is indifferent between these states; the superiority of A comes only with a pluralistic egalitarianism that independently assigns final value to welfare (or whatever one takes to be the appropriate object of equalization).
} 


\section{Figure 4.}

The second component of Christiano's defense of egalitarianism against the Leveling Down Objection starts by noting that all an egalitarian has to claim about unequal states is that in any such state there is something amiss or flawed, that things are less than ideal, and, as such, could be better in terms of equality. This can be done, however, in such a way that it will not be the case that any more equal state of affairs is better in terms of equality. Central to this second component of the defense is the idea that that we often explain how something is amiss or less than ideal in some respect by comparing it to an idealized version of itself. For instance, a house-hunter with a growing family might say that a four-bedroom house that he has been shown is not quite perfect because there are two bedrooms on each floor rather than all four on the same floor. ${ }^{19}$ It would be perfect, he might say, if it were exactly the same, except for the fact that all the bedrooms were on the same floor. Similarly, then, any unequal state of affairs can be shown to be flawed, or less than perfect in terms of equality, by comparing it to a more idealized version of itself. For instance, consider the simplified two-person world or state of affairs in which one person, A, has a welfare level of seven, and the other, B, has a welfare level of three $(7,3)$, as in $\mathrm{S} 3$ in Figure 5.

\begin{tabular}{cccc}
\hline & \multicolumn{3}{c}{ State of affairs } \\
\cline { 2 - 4 } Person & S1 & S2 & S3 \\
\hline A & 5 & 3 & 7 \\
B & 5 & 3 & 3 \\
\hline
\end{tabular}

Figure 5.

This state of affairs (S3) can be shown to be flawed or imperfect from an egalitarian point of view by comparing it to an idealized version of itself. The idealized version of itself, Christiano argues, "is to be understood as an equal and Pareto optimal distribution of the goods

\footnotetext{
${ }^{19}$ Of course a preference for all bedrooms being on the same floor is not universal. I am just assuming that the house-hunter has this preference for illustrative purposes.
} 
that are present in the best Pareto optimal state" (38). Thus, he claims, the ideal relative to $\mathrm{S} 3$, where the distribution is $(7,3)$, is actually $\mathrm{S} 1(5,5)$, a perfectly equal state which preserves the (total and average) welfare in the original unequal state. ${ }^{20}$ The reason for preserving in the ideal the (total and average) welfare in the original unequal state comes from the first component of Christiano's defense of egalitarianism, namely that (the value of) welfare is 'built into' equality, such that more welfare is better than less. ${ }^{21}$ Relative to the ideal S1 $(5,5)$, then, S3 $(7,3)$ is flawed or imperfect from an egalitarian point of view, just as the actual house the house-hunter viewed is flawed or imperfect relative to the idealized version of itself in which all the bedrooms are on the same floor.

Now imagine that the house-hunter's real estate agent were to show him a three-bedroom house with all the bedrooms on the same floor. Given that the house-hunter has a growing family, it is easy to imagine that he would prefer the four-bedroom house with two bedrooms on each floor. For, given his growing family, the four-bedroom house with two bedrooms on each floor is closer to the ideal than the threebedroom house with all the bedrooms on the same floor. We might say, then, that the while the four-bedroom house with two bedrooms on each floor is not perfect because the bedrooms are on separate floors, it does

\footnotetext{
${ }^{20}$ There might be some confusion here, because S1 $(5,5)$ is not Pareto-optimal relative to S3 $(7,3)$; it is, rather, Pareto-incomparable (though it is more equal according to the Pigou-Dalton Principle). However, Christiano is not claiming that the ideal is Paretooptimal relative to S3 $(7,3)$. Rather, he is claiming that the ideal is an equal and Paretooptimal distribution of the total units of welfare (10) in S3. The Pareto-optimality requirement here rules out equal distributions in which less than all ten units are distributed, e.g., $(4,4),(2,2)$, and $(0,0)$.

${ }^{21}$ It might be argued that in the real world it is not possible to preserve the welfare in the unequal state $(7,3)$ in a move to a more equal state because there are always transactions costs in redistribution. $(5,5)$, then, is not a feasible and more equal alternative to $(7,3)$. Feasible and more equal alternatives will have less total welfare, e.g., $(4.8,4.8)$, or $(5,4.7)$. Although he does not consider this particular concern, Christiano does say that the ideal equality point need not be feasible (38). This raises two concerns. First, if the ideal need not be feasible, why not make $(7,7)$ (or even $(14,14)$ ) the ideal of $(7,3)$ ? Second, it might seem inappropriate to evaluate states relative to an impossible ideal. If $(4.8,4.8)$ is the best equal and feasible alternative to $(7,3)$, it seems odd to deem it unjust because it falls short of an unrealistic $(5,5)$. Christiano has replies to each of these concerns. To the first, he says that the ideal should not be "purely utopian" (38). To the second, he argues that "justice is not always feasible as when two equally deserving persons create goods that are unequal in value and cannot be divided up" (38-39). These two replies together constitute what might be called 'moderate idealism', according to which it is acceptable to idealize-to abstract away from reality-only to a limited extent. Such moderate idealism, which avoids the extremes of realism and utopianism, is the emerging norm in ethics and political philosophy (see Vallier and Weber 2017). So perhaps Christiano can adequately address these concerns.
} 
not follow from this that any house with all the bedrooms on the same floor is better.

So too, Christiano claims, with the unequal state S3 $(7,3)$. It is flawed, or imperfect, from the egalitarian point of view because of its shortcomings with respect to S1 $(5,5)$. But it does not follow from this that any more equal state such as $\mathrm{S} 2(3,3)$ is better in terms of equality. For just as the four-bedroom house with bedrooms on different floors is closer to the ideal than the three-bedroom house with all the bedrooms on the same floor, Christiano claims, S3 $(7,3)$ is closer to the ideal, S1 $(5,5)$, than is S2 $(3,3)$. Thus, S2 is not better than S3 in terms of equality. Of course this claim-that the unequal state S3 $(7,3)$ is closer to the ideal S1 $(5,5)$ than the leveled down state S2 $(3,3)$-requires a rule or set of criteria for judging closeness to the ideal-for determining when one state is closer to, or a better approximation of, the ideal. Christiano does not actually provide such a rule or set of criteria. Instead, he suggests constraints on any such rule or set of criteria. The most important of these, for present purposes, is a Pareto-constraint: "the rule must never favor Pareto-inferior states over Pareto-superior states" (39). With this constraint, S3 $(7,3)$ is closer to the ideal, S1 $(5,5)$, than the leveled down state S2 $(3,3)$ because it is Pareto-superior. And the same will be true with any leveled down state, e.g., $(2,2),(5,3)$, and $(5,2) .^{22}$ Thus, Christiano concludes, leveled down states are not better in egalitarian terms. ${ }^{23}$

\section{ObJeCtions to Christiano's Defense}

There are, however, several objections to Christiano's defense of egalitarianism against the Leveling Down Objection. In the first part of the defense, he argues that welfare concerns are 'built into' equality of welfare. He is right, I will grant, that egalitarians (about welfare) must agree that more welfare is better than less, and must, therefore, prefer S1 $(5,5)$ to S2 $(3,3)$. But this does not make S2 better in egalitarian terms. For the argument shows only that the egalitarian is committed to

\footnotetext{
${ }^{22}$ Note that $(5,3)$ and $(5,2)$ are examples of the less extreme leveling down identified in Section II.

${ }^{23}$ In a co-authored paper, Christiano and Will Braynen (2008) present the same basic argument that Christiano offers in his book. What they add (409-419) is some detailed discussion of alternative ways of determining how far a given unequal state is from the (corresponding) ideal egalitarian distribution. They argue for a divergence rule of approximation over a difference summing rule of approximation. The difference between the two rules does not bear on my concerns here. What does matter is that both assume a Pareto-constraint: Pareto-superior states are always closer to the ideal than Pareto-inferior states.
} 
preferring more welfare than less, and thus preferring S1 to S2 allthings-considered. A commitment to equality of $\mathrm{X}$ may entail preferring more $\mathrm{X}$ to less; however, it does not show that $\mathrm{X}$ is a part of-'built into'-equality. There is a difference between egalitarians being committed to the value of welfare and welfare being literally built into or part of equality. Consider a different case. Some dance schools require their dancers to take ballet classes, even if the student is only interested in another form of dance, e.g., jazz or modern. The reason for this is that many of the steps, turns and progressions in jazz and modern dance just are ballet movements. In this case, it seems to me, ballet is a part of jazz or modern dance; it is built in, literally. But this does not seem to be the relation between equality and welfare, even if Christiano is right about what egalitarians are committed to. For in the case of equality, on Christiano's view, one is committed to something conceptually distinct. Thus, it seems to me, S1 $(5,5)$ is not better than S2 $(3,3)$ in egalitarian terms. Rather, it is better only in terms the egalitarian is committed to.

Now consider the second component of Christiano's defense of egalitarianism against the Leveling Down Objection. I will grant that what he says about establishing the ideal is correct-and, thus, that relative to S3 $(7,3)$, S1 $(5,5)$ is the ideal. What seems dubious, instead, is what he says about approximations to the ideal. Perhaps it is intuitive that S3 $(7,3)$ is closer to the ideal than S2 $(3,3)$. But, as noted earlier, there are less extreme cases of leveling down, for instance when the welfare level of the better-off is reduced, but not so much as to make them equal to the worse-off. So, for instance, a state 54 , in which the better-off have a welfare level of 5 while the worse-off are at $3(5,3)$, is a leveled down state relative to S3 $(7,3)$. See Figure 6 , which adds S4 to Figure 5.

\begin{tabular}{ccccc}
\hline & \multicolumn{5}{c}{ State of affairs } \\
\cline { 2 - 5 } Person & S1 & S2 & S3 & S4 \\
\hline A & 5 & 3 & 7 & 5 \\
B & 5 & 3 & 3 & 3 \\
\hline
\end{tabular}

Figure 6. 
It seems to me that it is far from intuitive that $S 3(7,3)$ is closer to the ideal $(5,5)$ than S4 $(5,3)$. To insist that S3 $(7,3)$ is closer to the ideal seems to attach greater significance to (preserving) welfare than to having a more equal distribution of welfare, because the more equal distribution in S4 $(5,3)$ does not count as much in determining which state is closer to the ideal as does the lower level of welfare. ${ }^{24}$ Indeed, Christiano's Pareto-constraint seems to assign lexical priority to (preserving) welfare over realizing a more equal distribution of that welfare. But even if it is agreed that in some important sense the egalitarian (with respect to welfare) is committed to placing value on welfare, this does not justify attaching greater significance to welfare such that S3 $(7,3)$ is closer to the ideal $(5,5)$ than S4 $(5,3)$, or even S2 $(3,3)$. Perhaps it is enough to show that egalitarians must balance considerations of equality (of welfare) and considerations of total or average welfare. But, depending on how the balance is struck, S4 $(5,3)$ may be a better approximation of the ideal $(5,5)$ than S3 $(7,3)$. Indeed, S2 could be a better approximation.

Of course Christiano might dismiss such appeals to intuition and alternative weightings of equality and welfare, insisting that he has a principled reason for thinking that S3 $(7,3)$ is closer to the ideal than S2 $(3,3)$, or any other leveled down state: the rules for approximation to the ideal must favor Pareto-superior states. However, simply insisting on such a Pareto-constraint would beg the question, as the debate about the Leveling Down Objection just is a debate over whether values must be Pareto-compatible (because leveled-down states are Pareto-inferior). Christiano does not merely insist on the Pareto-constraint. He says that it "follows from the importance of the well-being of all persons that is essential to the principle of equality" (Christiano 2008, 40). But as I have argued, even if it is true that a concern for equality of welfare commits one to valuing more welfare than less, it does not justify placing concerns for welfare ahead of equality. If one cares at all about equality of $\mathrm{X}$, then surely one is committed to the claim that more (total or average) $\mathrm{X}$ is better than less other things equal. But in cases of leveling down, other things are not equal: there is less welfare, but what there is

\footnotetext{
${ }^{24}$ Perhaps there is an intuitive sense that $\mathrm{S} 3(7,3)$ is closer to $\mathrm{S} 1(5,5)$ than $\mathrm{S} 4(5,3)$ is, because S3 and S1 have the same sum and average utility, but differ in terms of equality, while S4 and S1 have a different sum and average utility and differ in terms of equality. But the point still holds, because saying that all-things-considered S3 is closer to S1 than S4 requires assigning greater significance to utility considerations that equality considerations, because though both S4 and S3 are not as equal as S1, S4 is closer to S1 in terms of equality than S3 is.
} 
is more equally distributed. As such, the Pareto-constraint simply formalizes assigning greater significance or value to (preserving) welfare than the (more) equal distribution of welfare. It simply formalizes the unfounded assumption that improvements cannot be made by trading off welfare for greater equality.

\section{CONDITIONAL EgALITARIANISM}

Although he never makes the suggestion explicitly, Christiano's view is plausibly viewed as a version of Conditional Egalitarianism. ${ }^{25}$ According to Mason, recall, Conditional Egalitarianism is the view that (greater) equality is non-instrumentally valuable if and only if some are better off. ${ }^{26}$ Christiano's argument ultimately reaches exactly this conclusion..$^{27}$ For he argues, in short, that a state of affairs $\mathrm{X}$ is better in terms of equality only if it is closer to the relevant egalitarian ideal, and Paretoinferior states can never be closer to the ideal (than Pareto-superior states). It follows from this that leveled down states cannot be better with respect to equality, because, as noted earlier, leveled down states are by definition Pareto-inferior. ${ }^{28}$

Mason supports his claim that the value of (greater) equality is conditional on some being better off by appeal to intuition (Mason 2001, 250-251). But this can seem unsatisfactory. If (greater) equality is noninstrumentally valuable in some situations - when some are better offand not in others, then there should be some explanation for this variability. ${ }^{29}$ If someone suggests that chocolate cake (or the pleasure of eating chocolate cake) is good only if there is a full moon, we would

\footnotetext{
${ }^{25}$ Thanks again to David Dick for helping me to appreciate this point.

${ }^{26}$ Holtug (2007a, 50-52) argues compellingly that Conditional Egalitarianism should require further that it is more equal because some are better off. Temkin $(1987,171)$ makes the same point when he suggests a "person-affecting version of egalitarianism" according to which "concern about inequality is not merely a concern that inequality be removed, but that it is removed in a certain way, so as to benefit the worse off".

${ }^{27}$ Bertil Tungodden and Peter Vallentyne (2005) also reach a similar conclusion.

${ }^{28}$ Weaker forms of Conditional Egalitarianism are possible. Dale Dorsey $(2013,56)$ suggests the view that equality has non-instrumental value only if it does not make the worse-off any worse-off. However, as Dorsey admits, such Conditional Egalitarianism accepts that in some instances a leveled down state is better (at least with respect to equality), in particular when the very well off (or the 'ultra-rich') are leveled down (and those worse off neither gain nor lose). Perhaps, as Dorsey suggests, this degree of leveling down is acceptable. In this paper, however, I am restricting myself to considering whether there is an egalitarian view that can completely avoid the Leveling Down Objection. Dorsey freely admits that his version of Conditional Egalitarianism does not.

${ }^{29}$ Holtug (2007a, 56; 2010, 193-198) has emphasized this point. Also see Segall (2016, 29-31).
} 
surely insist on some explanation for this. What does the full moon have to do with chocolate cake? Of course this is a rhetorical question: the full moon has nothing to do with chocolate cake. ${ }^{30}$ And this is why we would not accept that the value of chocolate cake is conditional on there being a full moon. So if we are to accept that the value of equality is conditional on some being better off, there must be a connection between equality and some being better off sufficient to justify making the non-instrumental value of (greater) equality conditional on some being better off.

As we have seen, Christiano does argue for a connection between equality and welfare. He thinks that if equality with respect to $\mathrm{X}$ matters only if more $\mathrm{X}$ is better than less (recall the bread example). Thus, if equality with respect to welfare matters, then it must be that more welfare is better than less. ${ }^{31}$ This is insufficient, however, for reasons identified in the previous section. For Christiano establishes only that egalitarians (with respect to welfare) cannot be indifferent to welfare levels. But this is a far cry from a requirement that equality has value only if some are better off (just as it is a far cry from grounding a Pareto-constraint on rules of approximation to the ideal). If one accepts that the egalitarian with respect to welfare cannot be indifferent to welfare levels, then such an egalitarian must accept that higher welfare levels are better other things equal. But, as indicated in the previous section, with leveling down other things are not equal: in the leveled down state, the distribution of welfare is more equal. What was said in the previous section, then, shows that Christiano does not have an adequate explanation for holding that the value of equality is conditional on some being better off (just as he has no ground for a Pareto-constraint on rules of approximation to the ideal). Rather, he establishes only that the egalitarian (with respect to welfare) cannot be indifferent to welfare levels. But this is compatible with a leveled down state being better in virtue of the gain in equality being morally more significant than the loss in terms of welfare. ${ }^{32}$

\footnotetext{
${ }^{30}$ Of course there could be some kind of contingent connection, e.g., the best baker of chocolate cake only bakes when the moon is full. But typically there is not.

${ }^{31}$ Of course few, if any, would deny that more welfare is better than less (other things equal). But what matters for Christiano is that such a view is internal to egalitarianism, rather than a separate, independent commitment.

${ }^{32}$ One might, alternatively, try to ground Conditional Egalitarianism by directly appealing to the person-affecting principle (The Slogan, as Temkin calls it): something is good, e.g., greater equality, only if it is good for someone; thus, greater equality is good only if some are better off. Two points can be made here. First, Christiano
} 
Mason (2001) thinks that the demand for an explanation for the conditional value of equality is unreasonable-that in fact no explanation is required for the value of (greater) equality being conditional on some being better off. Many widely-accepted views about non-instrumental value, he notes, are defended by appeal to intuition, e.g., the claim that pleasure has non-instrumental value only if it is the product of a morally permissible act (or contemplation of such an act); pleasure that results from the performance or contemplation of an immoral act has no non-instrumental value. Indeed, he suggests that no other defense could be given. He says this explicitly about the case of the conditional value of equality - that it can only be defended by appeal to intuition (251).

It is hard to know how to settle such a dispute about whether an explanation is needed for these kind of claims about non-instrumental value. Even if it is agreed that justification has to end somewhere, people can disagree about where it ends-about when bedrock has been reached. With respect to the claim that the value of pleasure is conditional, Nils Holtug argues that to the extent that we are inclined to think so it is because there is an explanation for it, namely that pleasure is an inappropriate attitude to take towards immoral actions (Holtug 2007a, 61). Whether we agree with Holtug's explanation or not, the fact that such an explanation can be proposed undermines Mason's claim that such claims about non-instrumental value can only be defended by appeal to intuition-that it is somehow inconceivable that a deeper explanation can be provided. Perhaps there is a difference between the conditional value of pleasure and the conditional value of equality, such that the there is more reason to think that no further explanation can even be proposed in latter case. But there is surely no obvious difference, which puts the burden of proof on the side of those who think no further explanation is required (because somehow further explanation is inconceivable).

assiduously avoids appeal to the person-affecting principle. So this is not his approach. The likely reason he avoids it is the second point: the (justification of the) personaffecting principle is a well-known hornet's nest. Additionally, Holtug (2007a, 57-58) shows that an appeal to the person-affecting principle will not work, because while it requires that some must be better off in a more equal state for it to be better in a respect, it does not require that the state is more equal because some are better off. Mason $(2001,251)$ is also hesitant to appeal to the general claim that something cannot be good if it is good for no one. 
It might be held that no further explanation is required in cases like those under discussion if a view is widely accepted in the absence of an explanation-when those who accept it do so without being able to explain why they do. The thought here is that this is a hallmark of having reached bedrock: the best explanation for wide acceptance without an explanation is that there is no further explanation (possible). Some might make an argument along these lines for the conditional value of pleasure: it requires no further explanation because it is widelyaccepted even in the absence of an explanation. But there are at least two problems with this approach, even if we ignore the fact that the conditional value of pleasure is disputed. First, it is unclear that the best explanation for wide acceptance in the absence of an explanation is that bedrock has been reached, because such agreement might be the product of an underlying but not fully appreciated explanation. Indeed, I think this is Holtug's point about the conditional value of pleasure: to the extent that we accept the conditional value of pleasure it is because of an inchoate sense that pleasure is an inappropriate attitude to take towards immoral actions (or an inchoate sense of some other explanation). Second, even if it is allowed that there is widespread acceptance of the conditional value of pleasure, the conditional value of equality is surely quite contentious. Such disagreement undermines the suggestion that no further explanation is required because bedrock has been reached. It is further undermined by the fact that in the case of the conditional value of equality the dissenters are non-partisan: there are both egalitarians, e.g., Moderate Egalitarians such as Temkin, and critics of egalitarianism, e.g., Parfit, that think that a leveled down state is better with respect to equality-that the value of equality is not conditional on some being better off. These dissenters are divided on a different matter, as indicated earlier: they disagree about the significance of the fact that on the (telic) egalitarian view a leveled down state is better in a certain respect. Dissenters can sometimes be dismissed on the grounds that their dissent is ideologically driven, though people are often inclined to do so much too readily, without sufficient justification. ${ }^{33}$ But because dissent in the case of the conditional value of equality is non-partisan, such a dismissal is a nonstarter.

\footnotetext{
${ }^{33}$ The best examples of this come from sports-talk radio, where a caller's critical opinion of a team, or a player on a team, are immediately dismissed when it is revealed that the caller is a fan of a rival team.
} 
Neither Christiano nor Mason, then, offers an adequate defense of Conditional Egalitarianism. It requires a more robust defense, one that provides a satisfactory explanation for the conditional value of equality.

\section{The Prioritarian Alternative}

Recall that those with egalitarian (and teleological) leanings have an alternative to (telic) egalitarianism, namely prioritarianism. It has strong egalitarian tendencies in virtue of the priority it assigns to benefitting those worse off in absolute terms, and seems immune to the Leveling Down Objection because according to prioritarianism the only way to improve a situation is to make someone better off. As such, it presents a challenge to (telic) egalitarianism, as it offers most of the benefits without the costs. ${ }^{34}$ As noted earlier, Ingmar Persson (2013) and Campbell Brown (2003) both suggest an interesting response to this challenge: they argue that, contrary to initial appearances, prioritarianism too is subject to the Leveling Down Objection. Persson argues that prioritarianism is subject to the Leveling Down Objection because according to prioritarianism the average moral value of benefits (or utility) is higher in the leveled down state because benefits lost by those who are better off have relatively less moral value:

In the leveling down situation [... .] there is a reduction of the sum of benefits since the better off lose something, and the worse off gain nothing. But the average moral value of benefits goes up because it is the benefits with the lowest such value that are removed, i.e., the benefits which make some better off than others. (Persson 2013,4)

The leveled down state, then, is better with respect to the average moral value of benefits. It is better in some respect, then, even though no one is better off.

Brown's case that prioritarianism is subject to the Leveling Down Objection is rooted in his analysis of what it is for something to be better 'in a respect'. To simplify a bit, according to Brown's analysis A is better than $B$ in respect $r$ if and only if were there no other relevant differences between $A$ and $B$ the difference between $A$ and $B$ in respect $r$ would suffice to make A better than B all-things-considered. When this analysis is applied to a standard case of leveling down, as in Figure 1,

\footnotetext{
${ }^{34}$ Temkin (2002) complains that it only offers some of the benefits-that some egalitarian intuitions cannot be captured by prioritarianism.
} 
Brown claims, the prioritarian "is committed to the claim that $\mathrm{B}$ is better than A, in respect of equality" (Brown 2003, 117). ${ }^{35}$

At first pass, it is not at all clear either Persson or Brown has shown that prioritarianism is on a par with egalitarianism with respect to the Leveling Down Objection. Persson is right that in the leveled down state the average moral value of benefits is higher. But this does not seem to matter, because prioritarianism does not assign final (or noninstrumental) value to the average moral value of benefits. ${ }^{36}$ Just as the average moral value of benefits is higher in the leveled down state, average height could be greater, as could the percentage of the population that likes scrambled eggs. But it is no embarrassment to prioritarianism if average height is greater in the leveled down state, or if the percentage of the population that likes scrambled eggs is greater, because these are not things that have final (or non-instrumental) value on the prioritarian view. Similarly, then, it is no objection to prioritarianism that in the leveled down state the average moral value of benefits is greater because what matters to prioritarianism-what has final value-is not the average value of benefits but the total value of benefits. ${ }^{37}$ The average value of benefits may be greater, but that does not make it in any respect better if the average moral value of benefits has no value. ${ }^{38}$

Another way to put it is this. The problem for egalitarianism is that the leveled down state is better in egalitarian terms. If prioritarianism is

\footnotetext{
${ }^{35}$ Shlomi Segall (2015) also argues that prioritarianism cannot establish its superiority to egalitarianism by appealing to the Leveling Down Objection, though on slightly different grounds. His argument is that to avoid a troubling implication of prioritarianism in the case of an intrapersonal dilemma proposed by Otsuka and Voorhoeve (2009), prioritarianism must reject the Principle of Personal Good (PPG), a principle that Segall claims must be accepted to ground the Leveling Down Objection to egalitarianism. Though he does not make the point explicitly, rejection of PPG does seem to make one vulnerable to the Leveling Down Objection (or some analogous objection). It is beyond the scope of this paper to consider Segall's very interesting and distinct argument, in part because, as suggested, it flows from consideration of the very detailed critique of prioritarianism leveled by Otsuka and Voorhoeve. I discuss Otsuka and Voorhoeve's argument, and prominent responses to it, in Weber (2014).

${ }^{36}$ Porter $(2011,200-201)$ circles close to this point, as I note in the following.

${ }^{37}$ While average height or the percentage of population that likes scrambled eggs might be greater in the leveled down state, the average moral value of benefits must be greater in the leveled down state. However, it seems to me that even with this stronger modal connection prioritarianism is not committed to assigning final value to the average moral value of benefits.

${ }^{38}$ The point here, of course, is that 'greater' is a descriptive term, while 'better' is evaluative. Perhaps sometimes we use 'better' in a purely descriptive sense. Be that as it may, Persson's argument requires that the leveled down state is better in the evaluative sense.
} 
on a par with egalitarianism with respect to the Leveling Down Objection, then it must be the case that the leveled down state is better in prioritarian terms. But the fact that in the leveled down state the average moral value of benefits is higher does not establish that it is better in prioritarian terms (because prioritarianism does not assign final value to the average moral value of benefits). Persson, therefore, has not shown that prioritarianism is on a par with egalitarianism with respect to the Leveling Down Objection.

If this is right about Persson's case, then it seems the same can be said about Brown's case that prioritarianism is equally subject to the Leveling Down Objection. On Brown's analysis, the prioritarian is committed to saying that the leveled down state is better in terms of equality. But equality does not have final value according to prioritarianism. So the leveled down state is not better in prioritarian terms. There may be more equality in the leveled down state, but that does not make it better in virtue of the increased equality if equality has no final value. ${ }^{39}$

Although he does not develop the point in the same kind of detail, Thomas Porter has suggested a similar argument against Persson's argument that prioritarianism is subject to the Leveling Down Objection. ${ }^{40}$ In cases of leveling down, as Persson has emphasized, the average moral value of benefits (or utility) increases despite a decrease in overall benefits (or utility). Porter asks skeptically: "When the total and average of some value that you care about go in different directions, why not focus on the total alone and assign no moral significance to the [. . .] [increase] in the average?" (Porter 2011, 201).

Persson (2011), however, has argued in reply to Porter that it is not an option for the prioritarian to hold that the average moral value of benefits (utility) is a matter of indifference. He argues that if no value at all is assigned to it, then the view is indistinguishable from utilitarianism. The thought is this. For utilitarianism, all units of benefit (utility) have the same value. It does not matter who has the benefit, nor does it matter what his or her benefit level is. Therefore, utilitarianism entails that the average moral value of benefits is invariant. This is not true for prioritarianism, because, according to prioritarianism, some units of benefit have less (moral) value than others. In particular, units

\footnotetext{
${ }^{39}$ So, the point is, 'more' is descriptive just as 'greater' is.

${ }^{40}$ Holtug (2010, Chapter 8) discusses this issue at some length, and reaches similar conclusions.
} 
of benefit at a higher level of total benefit are less morally valuable than those at a lower level. Thus, if a person at a low total benefit level of 3 units gains an additional unit, this is more morally valuable than if a person at a high benefit level of 10 gains an additional unit. Because on a prioritarian view the value of additional units of benefit (utility) decreases, the average moral value of benefits decreases with Paretoimprovements and increases with leveling down to a Pareto-inferior state. Imagine, for instance, a two-person world $\mathrm{W}_{1}$ in which person $\mathrm{A}$ has two units of benefit and person $B$ has just one $(2,1)$. Assume a prioritarian view according to which the first unit of benefit (utility) for any person has a moral value of 10 while the second has a moral value of 4 . In $W_{1}$, then, the total moral value of the benefit is 24 , and the average moral value of a unit of benefit is 8 . Now imagine that $B$ is provided with another unit of benefit (utility), resulting in the twoperson world $\mathrm{W}_{2}$ in which both $\mathrm{A}$ and $\mathrm{B}$ enjoy two units of benefit or utility $(2,2)$. In $\mathrm{W}_{2}$, the total moral value of the benefits is higher, at 28 . However, the average moral value of benefits has decreased to 7 . Now consider a different variation from $\mathrm{W}_{1}$ : A loses a unit of benefit (utility), so that now both A and B have just one unit of benefit or utility $(1,1)$. Call the resulting state $\mathrm{W}_{3}$. In $\mathrm{W}_{3}$, the total moral value of benefit has decreased from 24 to 20, while the average moral value of units of benefit or utility has increased from 8 to 10 . What distinguishes prioritarianism from utilitarianism, then, is that the average moral value of benefits is variable. As such, Persson suggests, if one denies the moral significance of the average value of moral benefits, then one has abandoned prioritarianism in favor of utilitarianism.

There is, however, a simple reason to disagree with Persson's reply: the prioritiarian is not denying that the average value of benefit varies; rather, the prioritiarian is simply claiming that the (variable) average value of benefit (in a given state of affairs) has no moral significance or value in itself. Insofar as prioritarianism maintains that the average moral value of benefit is variable, it is not equivalent to utilitarianism. ${ }^{41}$

\footnotetext{
${ }^{41}$ Porter concludes similarly: "Indifference to changes in average prioritarian unit value need not imply indifference to changes in actual prioritarian value, since there can be changes in average prioritarian unit value without any changes in actual prioritarian unit values. It looks as if indifference to the changes in average prioritarian unit value, then, does not expose prioritarians to the accusation that their position is tantamount to utilitarianism" (Porter 2011, 202). Persson (2011, 308-309) does provide some further argument. He notes that Porter relies on cases in which benefits are either added to or subtracted from the benefits that recipients' already possess. He concedes that in these cases Porter is right: the prioritarian can maintain indifference to the
} 
Therefore, neither Persson nor Brown seems to have successfully shown that prioritarianism is equally vulnerable to the Leveling Down Objection. ${ }^{42}$ As such, without further argument it seems that the egalitarian must bite a bullet that the prioritarian does not have to bite, namely that leveling down can be an improvement at least in some respect. And if I am right about what I said about Moderate Egalitarianism, the (telic) egalitarian then must allow that it is at least possible that the leveled down state to be better all-things-considered.

\section{CONCLUSION}

In response to the Leveling Down Objection, defenders of egalitarianism have made several moves. Two have been considered in some detail here. ${ }^{43}$ The first is Christiano's view that claims that a leveled down state is not better even with respect to equality because the value of equality and the value of what is to be equalized are deeply intertwined. The second, made by both Persson and Brown, claims that prioritarianism too is subject to leveling down, and, as such, we should not be so troubled by egalitarianism's vulnerability to the Leveling Down Objection. I have argued that neither of these responses to the Leveling Down Objection are entirely convincing. This does not mean that (telic) egalitarianism must be abandoned, as one can insist that the Leveling Down Objection is not dispositive: even if (telic) egalitarianism has the consequence that leveled down states can be better in a respect, and therefore possibly better all-things-considered, this is an uncomfortable consequence rather than a decisive objection. The point of this paper, however, is that (telic) egalitarians may have to accept this

average moral value of benefits. But he argues that in cases in which there is a radical redistribution of benefits things are otherwise. But it seems to me that the same issue arises in such cases.

${ }^{42}$ As a last resort, it might be argued that Persson and Brown's arguments assume telic prioritarianism, leaving it open that deontic prioritiarianism is subject to the Leveling Down Objection (or some analogous objection). However, as in the case of egalitarianism, deontic views seem less rather than more likely to be subject to the Leveling Down Objection (or some analogous objection). Further, if telic prioritarianism is not subject to the Leveling Down Objection and telic egalitarianism is, as I have argued, then the egalitarian cannot claim that with respect to the Leveling Down Objection egalitarianism and prioritarianism are equally vulnerable.

${ }^{43}$ There are a variety of other approaches worth considering, including the view suggested by Otsuka and Voorhoeve (2009, 182-184) that the strength of a person's claims to benefits depends on the comparative strength of the claims of others. That, however, must be left for another time. 
uncomfortable consequence, as the two attempts discussed here to deny it or lessen its significance are unsuccessful.

\section{REFERENCES}

Brown, Campbell. 2003. “Giving Up Leveling Down.” Economics \& Philosophy 19 (1): 111-134.

Christiano, Thomas. 2008. The Constitution of Equality: Democratic Authority and its Limits. Oxford: Oxford University Press.

Christiano, Thomas, and Will Braynen. 2008. "Inequality, Injustice and Leveling Down." Ratio 21 (4): 392-420.

Crisp, Roger. 2003a. "Egalitarianism and Compassion.” Ethics 114 (1): 119-126.

Crisp, Roger. 2003b. “Equality, Priority, and Compassion.” Ethics 113 (4): 745-763.

Dorsey, Dale. 2013. "Equality-Tempered Prioritarianism.” Politics, Philosophy \& Economics 13 (1): 45-61.

Holtug, Nils. 2007a. “A Note on Conditional Egalitarianism.” Economics \& Philosophy 23 (1): 45-63.

Holtug, Nils. 2007b. "Prioritarianism." In Egalitarianism: New Essays on the Nature and Value of Equality, edited by Nils Holtug and Kasper Lippert-Rasmussen, 125-156. Oxford: Clarendon Press.

Holtug, Nils. 2010. Persons, Interests, and Justice. Oxford: Oxford University Press.

Lippert-Rasmussen, Kasper. 2007. "The Insignificance of the Distinction Between Telic and Deontic Egalitarianism." In Egalitarianism: New Essays on the Nature and Value of Equality, edited by Nils Holtug and Kasper Lippert-Rasmussen, 101-124. Oxford: Clarendon Press.

Mason, Andrew. 2001. "Egalitarianism and the Leveling Down Objection." Analysis 61 (3): 246-254.

McKerlie, Dennis. 1996. "Equality.” Ethics 106 (2): 274-296.

O’Neill, Martin. 2008. "What Should Egalitarians Believe?" Philosophy \& Public Affairs 36 (2): 119-156.

Otsuka, Michael, and Alex Voorhoeve. 2009. "Why It Matters That Some Are Worse off than Others: An Argument against the Priority View." Philosophy \& Public Affairs 37 (2): 171-199.

Parfit, Derek. 1997. "Equality and Priority.” Ratio X: 202-221

Parfit, Derek. 2012. “Another Defence of the Priority View.” Utilitas 24 (3): 399-440.

Persson, Ingmar. 2011. Prioritarianism, Leveling Down and Welfare Diffusion. Ethical Theory and Moral Practice 14 (3): 307-311.

Persson, Ingmar. 2013. "Prioritarianism." In International Encyclopedia of Ethics, edited by Hugh Lafollete. Hoboken, NJ: Wiley.

Porter, Thomas. 2011. "Prioritarianism and the Leveling Down Objection." Ethical Theory and Moral Practice 14 (2): 197-206.

Segall, Shlomi. 2015. "In Defense of Priority (and Equality)." Politics, Philosophy, and Economics 14 (4): 343-364.

Segall, Shlomi, 2016. Why Inequality Matters: Luck Egalitarianism, Its Meaning and Value. Cambridge: Cambridge University Press.

Temkin, Larry. 1987. "Intransitivity and the Mere Addition Paradox." Philosophy \& Public Affairs 16 (2): 138-187. 
Temkin, Larry. 1993a. "Harmful Goods, Harmless Bads." In Value, Well-being and Morality, edited by R. G. Frey, R. G., and Christopher Morris, 290-324. Cambridge: Cambridge University Press.

Temkin, Larry. 1993b. Inequality. Oxford: Oxford University Press.

Temkin, Larry. 2002. "Equality, Priority, and the Leveling Down Objection." In The Ideal of Equality, edited by Matthew Clayton and Andrew Williams, 126-161. Basingstoke: Palgrave-Macmillan.

Temkin, Larry. 2003a. "Egalitarianism Defended.” Ethics 113 (4): 764-782.

Temkin, Larry. 2003b. “Equality, Priority, or What?" Economics \& Philosophy 19 (1): 6187.

Tungodden, Bertil. 2003. “The Value of Equality.” Economics \& Philosophy 19 (1): 1-44.

Tungodden, Bertil, and Peter Vallentyne. 2005. "On the Possibility of Paretian Egalitarianism.” Journal of Philosophy 102 (3): 126-154.

Vallier, Kevin, and Michael Weber, eds. 2017. Political Utopias: Contemporary Debates. Oxford: Oxford University Press.

Weber, Michael. 2014. "Prioritarianism." Philosophy Compass 9 (11): 756-768.

Williams, Andrew. 2012. “The Priority View Bites the Dust?” Utilitas 24 (3): 315-331.

Michael Weber is Professor of Philosophy at Bowling Green State University, and Department Chair.

Contact e-mail: <meweber@bgsu.edu> 